The Journal of

Thoracic and

Cardiovascular

Surgery

Vol 124, No. 3, September 2002

\title{
Developmental and neurologic outcomes late after neonatal corrective surgery
}

Pedro J. del Nido, MD

See related article on page 448 .
From the Department of Cardiac Surgery, Children's Hospital, Harvard Medical School, Boston, Mass.

Received for publication Jan 24, 2002; accepted for publication Feb 10, 2002.

Address for reprints: Pedro J. del Nido, MD, Department of Cardiac Surgery, Children's Hospital, 300 Longwood Ave, Boston, MA 02115 (E-mail: Pedro.delnido@ tch.harvard.edu).

J Thorac Cardiovasc Surg 2002;124:425-7

Copyright $(\odot 2002$ by The American Association for Thoracic Surgery

$0022-5223 / 2002 \$ 35.00+0 \quad \mathbf{1 2 / 1 / 1 2 4 2 3 8}$

doi:10.1067/mtc.2002.124238

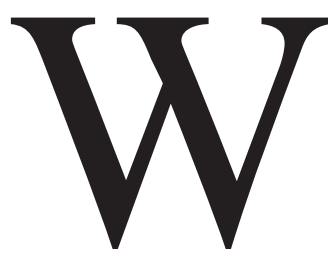

ith the many advances in treatment of congenital heart defects, including prenatal detection, improved perioperative management, and surgical technique, operative results for most complex congenital heart lesions requiring neonatal intervention have steadily improved. Now that operative mortality is low for many lesions, the focus has shifted from assessment of short-term results to measures of late functional outcome, including assessment of hemodynamic and neurodevelopmental statuses. Investigators in this field have recognized, however, that the wide range of anatomic defects treated may have direct and indirect effects on late outcomes, making the design of experiments aimed at evaluating specific management techniques difficult, and these studies often require a large cohort to establish statistical power. The group of infants born with the D-transposition of the great arteries represents a unique study cohort in that the anatomic defect results in a predictable clinical presentation and the preoperative and surgical management have now become standardized in most institutions. At best, the uniformity of age, low incidence of associated important hemodynamic defects, standardized surgical technique, and very low rate of associated noncardiac genetic defects makes this an ideal group for both retrospective and prospective randomized trials. Thus many clinical trials studying the effects of specific surgical techniques, such as the use of deep hypothermic circulatory arrest, ${ }^{1} \mathrm{pH}$ management on bypass, ${ }^{2}$ and degree of hemodilution, have been done in this particular patient population. Despite the apparent homogeneity of this group however, it is important to recognize that there are a number of uncontrolled clinical variables that may significantly affect the end points being measured. In particular, neurologic and developmental measures determined late after surgery are likely to be greatly affected by such factors as severe cyanosis, metabolic acidosis, and hemodynamic instability, which may be present to varying degrees in the immediate neonatal period before surgery. The deleterious effects of cardiopulmonary bypass and circulatory arrest may further compound the injury imposed by these stresses. ${ }^{3}$ It is also important to recognize that with this particular anatomic defect surgical technique and experience of the surgeon may have an impact on hemodynamic stability in the early postoperative period, which may add to the neurologic injury. Therefore, although the operative technique has been standardized, the surgeon's "learning curve" may also adversely affect late neurodevelopmental outcomes among these patients. ${ }^{4}$

Several methods have been developed to assess the effects of cardiac surgery on brain function and integrity in neonates and infants. Intraoperative indices of neurologic function have been used in pediatric and adult patients. These tests include metabolic studies (such as measurements of cerebral oxygen consumption or cerebral venous oxygen content), return of electroencephalographic activity after 
bypass, presence of clinical or subclinical seizures early after surgery, and assessment of gross neurologic defects, such as motor or sensory dysfunction and choreoathetosis. Other than the presence of gross neurologic deficits or clinical seizures, the significance of intraoperative measurements with respect to long-term neurodevelopmental outcome remains controversial. To more clearly assess the impact of surgical interventions on neurodevelopmental outcome, evaluation late after surgery is therefore necessary. The complexity of assessing neurologic and developmental status in young children, however, requires expertise combined with application of a wide range of tests that are specifically designed to evaluate motor, sensory, and cognitive brain function. To fully define neurodevelopmental outcome, investigators in the field assess a number of specific performance variables with a battery of tests that are age specific. The goal is to assess motor skills (fine and gross), speech, and development, including general intelligence as well as language comprehension and vocabulary, and in some studies academic achievement has also been assessed in an effort to measure acquired skills and presumably the child's ability to learn these skills. As with all neurodevelopmental testing, the specific tests used must be appropriate for the age of the child, and it is generally agreed that sensitivity and specificity of these tests are limited in very young children and improve somewhat with age.

Hövels-Gürich and associates ${ }^{5}$ used such a multidisciplinary approach for assessment of neurodevelopmental outcomes late after neonatal cardiac surgery in a cohort of 60 children who had undergone a neonatal arterial switch 8 to 14 years previously. Their findings corroborate previously published studies, indicating that the incidence of significant neurologic and developmental deficits present among children who had undergone neonatal cardiac surgery was relatively high. The severity of the defects varied from gross motor deficits to subtle impairment of fine motor skills and speech and language abilities. In the study of Hövels-Gürich and associates, ${ }^{5}$ statistical analysis indicated that preoperative acidosis and hypoxia, prolonged cardiopulmonary bypass, and postoperative hemodynamic instability were significant and independent predictive risk factors for worse outcomes. Importantly, the operative technique included a relatively short pre-circulatory arrest cooling period (10.8 \pm 2.7 minutes), a prolonged circulatory arrest period (60 \pm 3 minutes), $\mathrm{pH}$-stat management, and moderate hemodilution, with a hematocrit of $25 \%$. In a subgroup of the patients, low-flow bypass was used after the circulatory arrest period and before rewarming, during completion of the repair. The circulatory arrest period was long but relatively uniform, and the authors were unable to detect a significant correlation between circulatory arrest time and neurologic outcome. This latter finding is in contrast to previous studies, in which circulatory arrest time had a significant impact on late neurodevelopmental outcomes in a large cohort of infants with the same diagnosis undergoing anatomic repair of transposition. ${ }^{1}$

Although it is tempting in these studies to isolate one parameter for analysis, such as circulatory arrest time, it is important to delve more deeply into the details of the study design to draw conclusions. As with all clinical studies, the presence or absence of a correlation between a specific intervention and outcome parameters is often determined by the statistical power of the study design. It is usually more difficult to definitively demonstrate a lack of correlation, particularly in complex studies, where a number of variables may interact. Thus the ability to detect a subtle association between different variables is affected greatly by the cohort size. This factor, along with the relatively narrow range of circulatory arrest periods, may have limited the power to identify important associations in the study by HövelsGürich and associates. ${ }^{5}$

Another aspect that may explain the difference in findings between the study of Hövels-Gürich and associates 5 and that of the Boston Circulatory Arrest Study Group ${ }^{1}$ is the observation that the presence of a large ventricular septal defect (VSD) was an independent risk factor for lower IQ scores, higher incidence of seizures, and speech deficit in the latter study. In this study by Hövels-Gürich and associates, ${ }^{5}$ very few patients had a significant VSD. Although the Boston Circulatory Arrest Study Group did find significant differences in late outcomes between low-flow and circulatory arrest groups among infants with transposition and intact ventricular septum, the differences were much more marked among those infants with large VSDs. It is interesting to note that presence of a VSD was a risk factor despite the fact that the preoperative status of these infants was better than those with intact ventricular septum, in that arterial oxygenation was higher and a lower percentage required preoperative intubation.

As more late follow-up studies are performed on children who have undergone neonatal cardiac surgery, many of the current controversies regarding optimal management are likely to be resolved. However, there is general agreement that despite the many advances in cardiopulmonary bypass, surgical techniques, and preoperative stabilization, there is a higher incidence of detectable neurologic deficits, including speech and language, fine motor performance, and cognitive skills, in young children undergoing cardiac surgery than in the general population. Therefore it is clear that further improvements in the surgical management of infants with complex congenital heart defects are required, and evaluation of these new techniques will likely come from prospective, randomized trials with large patient cohorts and longterm follow-up. 


\section{References}

1. Bellinger DC, Wypij D, Kuban KC, Rappaport LA, Hickey PR, Wernovsky G, et al. Developmental and neurological status of children at 4 years of age after heart surgery with hypothermic circulatory arrest or low-flow cardiopulmonary bypass. Circulation. 1999;100: 526-32.

2. Bellinger DC, Wypij D, du Plessis AJ, Rappaport LA, Riviello J, Jonas RA, et al. Developmental and neurologic effects of alpha-stat versus $\mathrm{pH}$-stat strategies for deep hypothermic cardiopulmonary bypass in infants. J Thorac Cardiovasc Surg. 2001;121:374-83.
3. Newburger JW, Jonas RA, Wernovsky G, Wypij D, Hickey PR, Kuban $\mathrm{KC}$, et al. A comparison of the perioperative neurologic effects of hypothermic circulatory arrest versus low-flow cardiopulmonary bypass in infant heart surgery. $N$ Engl J Med. 1993;329:1057-64.

4. de Leval MR. Lessons from the arterial-switch operation. Lancet. 2001;357:1814.

5. Hövels-Gürich HH, Seghaye MC, Schnitker R, Wiesner M, Huber W, Minkenberg $\mathrm{R}$, et al. Long-term neurodevelopmental outcomes in school-aged children after neonatal arterial switch operation. J Thorac Cardiovasc Surg. 2002;124:448-58.

\section{JTCVS On-Line Manuscript Submission and Review Please visit http://www.editorialmanager.com/jtcvs/}

Effective September 15, 2001, authors and reviewers may submit manuscripts and reviews electronically via Editorial Manager, our new Web-based system with full electronic submission, review, and status update capabilities.

As we move from paper to electronic submissions, the Editorial Office will make proxy submissions of all manuscripts accompanied by a diskette containing the electronic files of the text, tables, and figures. Editors, authors, and reviewers will receive automatic e-mails when significant events occur.

We strongly encourage all authors and reviewers to use Editorial Manager. Although we will continue to accommodate the submission of paper manuscripts for some months, our goal is to be completely electronic within 9 to 12 months.

All individuals currently in our database for whom we have e-mail addresses will receive via e-mail a system-assigned username and password that can be used to log in to the system without prior registration. All those not receiving the e-mail must register the first time they use the system.

As with any broad systemic change, the conversion to the new system will take some time to complete. We ask your patience as we replace our in-office database with the new system. We also encourage you to take advantage of the speed and efficiency that the new system will provide for us all: editor, author, reviewer, and publisher. 